\title{
Serum Granulocyte Colony-Stimulating Factor and Alzheimer's Disease
}

\author{
Robert C. Barber ${ }^{a}$ b Melissa I. Edwards ${ }^{e}$ Guanghua Xiao $^{f}$ \\ Ryan M. Huebingerg Ramon Diaz-Arrastia ${ }^{h}$ Kirk C. Wilhelmsen ${ }^{i}$ \\ James R. Hall ${ }^{a, c}$ Sid E. O'Bryant ${ }^{a, d}$ for the Texas Alzheimer's \\ Research and Care Consortium ${ }^{1}$
}

a Institute of Aging and Alzheimer's Disease Research and Departments of b Pharmacology and Neuroscience, ' Psychiatry and ${ }^{\mathrm{d}}$ Internal Medicine, University of North Texas Health Science Center, Fort Worth, Tex., 'Department of Neurology, F. Marie Hall Institute for Rural and Community Health, Texas Tech University Health Sciences Center, Lubbock, Tex., Departments of ${ }^{\mathrm{f}}$ Clinical Sciences and

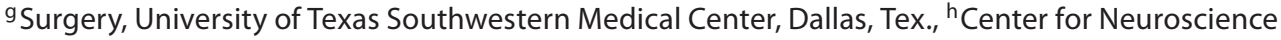
and Regenerative Medicine, Uniformed Services University of the Health Sciences, Bethesda, Md., and 'Department of Genetics, University of North Carolina at Chapel Hill, Chapel Hill, N.C., USA

\section{Key Words}

Granulocyte colony-stimulating factor - Alzheimer's disease - Inflammation · Serum proteins • Mini-Mental State Examination · Clinical Dementia Rating-Sum of Boxes

\begin{abstract}
Background: Granulocyte colony-stimulating factor (G-CSF) promotes the survival and function of neutrophils. G-CSF is also a neurotrophic factor, increasing neuroplasticity and suppressing apoptosis. Methods: We analyzed G-CSF levels in 197 patients with probable Alzheimer's disease (AD) and 203 cognitively normal controls (NCs) from a longitudinal study by the Texas Alzheimer's Research and Care Consortium (TARCC). Data were analyzed by regression with adjustment for age, education, gender and APOE4 status. Results: Serum G-CSF was significantly lower in AD patients than in NCs $(\beta=-0.073 ; p=0.008)$. However, among AD patients, higher
\end{abstract}

\footnotetext{
1 Investigators from the Texas Alzheimer's Research and Care Consortium: Baylor College of Medicine: Rachelle Doody, MD, PhD, Susan Rountree, MD, Valory Pavlik, PhD, Wen Chan, PhD, Paul Massman, PhD, Eveleen Darby, Tracy Evans, RN, and Aisha Khaleeq; Texas Tech University Health Science Center: Benjamin Williams, MD, Gregory Schrimsher, PhD, Andrew Dentino, MD, and Ronnie Orozco; University of North Texas Health Science Center: Thomas Fairchild, PhD, Janice Knebl, DO, Douglas Mains, and Lisa Alvarez; University of Texas Southwestern Medical Center: Perrie Adams, PhD, Roger Rosenberg, MD, Myron Weiner, MD, Mary Quiceno, MD, Joan Reisch, PhD, Doris Svetlik, Amy Werry, and Janet Smith; University of Texas Health Science Center - San Antonio: Donald Royall, MD, Raymond Palmer, PhD, and Marsha Polk.
} 
serum G-CSF was significantly associated with increased disease severity, as indicated by lower Mini-Mental State Examination scores $(\beta=-0.178 ; p=0.014)$ and higher scores on the global Clinical Dementia Rating (CDR) scale $(\beta=0.170 ; p=0.018)$ and CDR Sum of Boxes $(\beta=0.157 ; p=$ 0.035). Conclusions: G-CSF appears to have a complex relationship with AD pathogenesis and may reflect different pathophysiologic processes at different illness stages.

Copyright $\odot 2012$ S. Karger AG, Basel

\section{Introduction}

Granulocyte colony-stimulating factor (G-CSF) is a hematopoietic growth factor that helps regulate the mobilization of bone marrow progenitor cells and promotes neuroprotection and neurogenesis $[1,2]$. G-CSF is produced by immune cells, particularly macrophages, as well as endothelial cells. Human G-CSF exists as a 174- or 180-amino-acid-long protein, with the 174-amino-acid form being more abundant and more active [3]. The G-CSF receptor is present on hematopoietic cells of the bone marrow and, when activated by G-CSF, initiates the proliferation and differentiation of progenitor cells into mature granulocytes [1]. The G-CSF receptor is also expressed by neurons in the brain and spinal cord, enabling GCSF to act as a neurotrophic factor. In the central nervous system, G-CSF induces neurogenesis, counteracts apoptosis and increases neuroplasticity $[4,5]$.

In rodent models of Alzheimer's disease (AD), G-CSF treatment decreased the amyloid burden in the brain $[6,7]$, reversed cognitive impairment [7] and reduced chronic inflammation [8]. In other studies, G-CSF administered to mice following ischemic injury has been shown to stimulate the proliferation of microglia [9].

In the present study, we sought to determine whether the serum G-CSF level significantly differs between AD and control subjects and whether serum G-CSF levels are correlated with clinical measures of disease severity.

\section{Methods}

\section{Participants}

Participants included 400 individuals (197 diagnosed with probable AD and 203 cognitively normal controls; NCs) enrolled in the Texas Alzheimer's Research and Care Consortium (TARCC) longitudinal research cohort. The methodology of the TARCC project has been described in detail elsewhere. Briefly, each participant completed an annual examination consisting of a medical examination, interview, blood draw and neuropsychological testing at one of the five TARCC sites. The TARCC core neuropsychological battery consists of commonly utilized instruments in $\mathrm{AD}$ clinical/research settings along with measures assessing global functioning, i.e. the Mini-Mental State Examination (MMSE) [10] and the Clinical Dementia Rating (CDR) scale [11]. These data were reviewed by each site's consensus committee, and a diagnosis was assigned according to NINCDS-ADRDA criteria [12]. NCs were judged to be within normal limits on neuropsychological testing by consensus review. Participants with AD were largely in the mild-to-moderate range. The TARCC project has Institutional Review Board approval at all member institutions, and all participants and/or caregivers signed written informed consent documents.

Assays

Non-fasting samples were collected in serum-separating tubes during clinical evaluations, allowed to clot at room temperature for $1 \mathrm{~h}$, centrifuged, aliquoted and stored at $-80^{\circ} \mathrm{C}$ 
Table 1. Demographic information of the 400 participants in the TARCC longitudinal research cohort

\begin{tabular}{llll}
\hline Variable & $\mathrm{AD}(\mathrm{n}=197)$ & $\mathrm{NC}(\mathrm{n}=203)$ & $\mathrm{p}$ value \\
\hline $\begin{array}{l}\text { Male gender } \\
\text { Age, years }\end{array}$ & $34.5 \%$ & $32.0 \%$ & 0.67 \\
$\quad$ Median & 79.0 & 70.0 & \\
$\quad$ Range & $57.0-94.0$ & $52.0-90.0$ & $<0.0001$ \\
Education, years & & & \\
$\quad$ Median & 14 & 16 & \\
$\quad$ Range & $0-22$ & $10-25$ & $<0.0001$ \\
APOE4 status & & & \\
$\quad-/-$ & 71 & 147 & $<0.0001$ \\
$\quad-/+$ & 83 & 48 & \\
$\quad+/+$ & 27 & 5 & \\
$\quad$ Unknown & 16 & 3 & \\
Hispanic ethnicity & $3.6 \%$ & $5.4 \%$ & 0.47 \\
Race & & & \\
$\quad$ White & 187 & 190 & \\
$\quad$ Non-White & 10 & 13 & 0.67 \\
\hline
\end{tabular}

in polypropylene vials. Frozen samples were sent to Rules Based Medicine (www.rulesbasedmedicine.com, Austin, Tex., USA), where they were thawed for assay without additional freeze-thaw cycles. Rules Based Medicine conducted a multiplex immunoassay via their human Multi-Analyte Profiling (human MAP) technology. Multiple proteins, including GCSF, were quantified through multiplex fluorescent immunoassay utilizing colored microspheres with protein-specific antibodies. For G-CSF, the least detectable dose was $5 \mathrm{pg} / \mathrm{ml}$, inter-run coefficient of variation was $<10 \%$, dynamic range was $1-5,000 \mathrm{pg} / \mathrm{ml}$, overall spiked standard recovery for serum was $70 \%$ and cross-reactivity with other human MAP analytes was $<1 \%$. Assays conducted by this company utilizing this platform, including TARCC data, have been published elsewhere [13, 14].

Analyses

Statistical analyses were conducted using SPSS version 19.0 (IBM). Unadjusted analyses were conducted by either $t$ test for continuous or Mann-Whitney $U$ test for categorical variables. Serum G-CSF levels were compared across diagnostic categories (AD vs. NC), and associations between G-CSF levels and disease severity (MMSE and CDR scores) were assessed by multivariate regression. All regression models included age, sex, years of education, race and APOE4 carrier status as covariates. Statistical significance was declared for $\mathrm{p}$ values $<0.05$. In follow-up analyses, the sample was stratified on APOE4 carrier status (-/- vs. $-/+$ and $+/+$ ), and the analyses described above were repeated.

\section{Results}

Demographic characteristics of the study population are shown in table 1 . Relative to controls, AD patients did not significantly differ with respect to sex, race or Hispanic ethnicity; however, they were significantly older (median age, 79 vs. 70 years; $p<0.001$ ), less educated (median years of education, 14 vs. $16 ; \mathrm{p}<0.001$ ) and more likely to carry one or more copies of the APOE $\varepsilon 4$ allele (APOE4 carriers, 13.7 vs. $2.5 \%$; p < 0.001). 
Table 2. Odds ratio for disease status following adjustment for multiple factors as determined by multivariate logistic regression

\begin{tabular}{lrlllrr}
\hline Variable & B & SE & $\operatorname{Exp}(\mathrm{B})$ & \multicolumn{2}{l}{$95 \% \mathrm{CI} \operatorname{Exp}(\mathrm{B})$} & \multirow{2}{*}{$\mathrm{p} \mathrm{value}$} \\
\cline { 1 - 1 } & & & & lower & upper & \\
\hline Age & 0.088 & 0.014 & 1.092 & 1.061 & 1.123 & $<0.001$ \\
Sex & -0.434 & 0.263 & 0.648 & 0.387 & 1.085 & 0.099 \\
Education & -0.162 & 0.043 & 0.851 & 0.781 & 0.926 & $<0.001$ \\
APOE4 & 1.623 & 0.255 & 5.066 & 3.074 & 8.349 & $<0.001$ \\
G-CSF & -0.073 & 0.028 & 0.930 & 0.881 & 0.981 & 0.008 \\
\hline
\end{tabular}

Age, education and G-CSF concentration were analyzed as continuous variables. Odds ratios are for each additional year of age and year of education.

Table 3. Multivariate logistic regression for MMSE scores of participants in the TARCC longitudinal cohort with a diagnosis of probable $\mathrm{AD}$

\begin{tabular}{llllll}
\hline Variable & \multicolumn{2}{l}{$\begin{array}{l}\text { Unstandardized } \\
\text { coefficients }\end{array}$} & \multicolumn{2}{l}{$\begin{array}{l}\text { Standardized } \\
\text { coefficient } \beta\end{array}$} & $\mathrm{t}$ value \\
\cline { 2 - 4 } $\mathrm{B}$ & Std error & & \\
\hline Age & 0.045 & 0.056 & 0.059 & 0.796 & 0.427 \\
Sex & 0.128 & 0.973 & 0.010 & 0.132 & 0.895 \\
Education & 0.098 & 0.140 & 0.051 & 0.701 & 0.484 \\
APOE4 & -0.710 & 0.932 & -0.056 & -0.761 & 0.447 \\
G-CSF & -0.256 & 0.104 & -0.178 & -2.469 & 0.014 \\
\hline
\end{tabular}

Age, education and G-CSF were analyzed as continuous variables. APOE4 status was determined by the carriage of at least one APOE4 allele.

Table 4. Multivariate logistic regression for global CDR scores of participants in the TARCC longitudinal cohort with a diagnosis of probable AD

\begin{tabular}{|c|c|c|c|c|c|}
\hline \multirow[t]{2}{*}{ Variable } & \multicolumn{2}{|c|}{$\begin{array}{l}\text { Unstandardized } \\
\text { coefficients }\end{array}$} & \multirow[t]{2}{*}{$\begin{array}{l}\text { Standardized } \\
\text { coefficient } \beta\end{array}$} & \multirow[t]{2}{*}{$\mathrm{t}$} & \multirow[t]{2}{*}{$\mathrm{p}$ value } \\
\hline & B & Std error & & & \\
\hline Age & 0.011 & 0.007 & 0.126 & 1.701 & 0.091 \\
\hline Sex & 0.081 & 0.116 & 0.052 & 0.704 & 0.482 \\
\hline Education & -0.009 & 0.016 & -0.038 & -0.531 & 0.596 \\
\hline APOE4 & 0.001 & 0.111 & 0.001 & 0.013 & 0.990 \\
\hline G-CSF & 0.030 & 0.012 & 0.170 & 2.379 & 0.018 \\
\hline
\end{tabular}

Age, education and G-CSF were analyzed as continuous variables. APOE4 status was determined by the carriage of at least one APOE4 allele. 
Table 5. Multivariate logistic regression for CDR-Sum of Boxes scores of participants in the TARCC longitudinal cohort with a diagnosis of probable $\mathrm{AD}$

\begin{tabular}{|c|c|c|c|c|c|}
\hline \multirow[t]{2}{*}{ Variable } & \multicolumn{2}{|c|}{$\begin{array}{l}\text { Unstandardized } \\
\text { coefficients }\end{array}$} & \multirow[t]{2}{*}{$\begin{array}{l}\text { Standardized } \\
\text { coefficient } \beta\end{array}$} & \multirow[t]{2}{*}{$\mathrm{t}$} & \multirow[t]{2}{*}{$\mathrm{p}$ value } \\
\hline & B & Std error & & & \\
\hline Age & 0.058 & 0.040 & 0.109 & 1.462 & 0.145 \\
\hline Sex & 0.376 & 0.686 & 0.040 & 0.549 & 0.584 \\
\hline Education & -0.072 & 0.097 & -0.054 & -0.745 & 0.457 \\
\hline APOE4 & 0.083 & 0.661 & 0.009 & 0.126 & 0.900 \\
\hline G-CSF & 0.157 & 0.074 & 0.153 & 2.126 & 0.035 \\
\hline
\end{tabular}

Age, education and G-CSF were analyzed as continuous variables. APOE4 status was determined by the carriage of at least one APOE4 allele.

Table 6. Multivariate logistic regression for association between serum G-CSF levels and neuropsychological test scores, following adjustment for age, gender, years of education and APOE4 status

\begin{tabular}{|c|c|c|c|c|}
\hline \multirow[t]{2}{*}{ Variable } & \multicolumn{2}{|l|}{$\mathrm{AD}$ G-CSF } & \multicolumn{2}{|l|}{ NC G-CSF } \\
\hline & Standardized $\beta$ & $\mathrm{p}$ value & Standardized $\beta$ & $\mathrm{p}$ value \\
\hline COWAT & 0.028 & 0.720 & -0.053 & 0.463 \\
\hline Boston 60 & 0.025 & 0.735 & 0.011 & 0.864 \\
\hline AMNART & -0.094 & 0.146 & -0.068 & 0.313 \\
\hline Trails A & -0.095 & 0.248 & -0.099 & 0.206 \\
\hline Trails B & 0.042 & 0.659 & 0.092 & 0.240 \\
\hline Estimated VIQ & -0.067 & 0.248 & -0.081 & 0.160 \\
\hline Digit Span Total & -0.180 & $0.011^{*}$ & -0.003 & 0.963 \\
\hline LM I & -0.006 & 0.944 & 0.158 & 0.044 \\
\hline LM II & -0.085 & 0.256 & 0.180 & $0.022^{*}$ \\
\hline VR I & -0.047 & 0.548 & 0.021 & 0.786 \\
\hline VR II & -0.073 & 0.319 & 0.059 & 0.440 \\
\hline
\end{tabular}

Estimated VIQ = Estimated premorbid intelligence quotient; LM 1 = immediate logical memory; LM II = delayed logical memory; VR I = immediate visual recall; VR II = delayed visual recall .

* Significant after Bonferroni adjustment for multiple testing.

Median serum G-CSF levels were significantly lower in AD cases compared to controls (8.1 vs. $9.9 \mathrm{pg} / \mathrm{ml}$, respectively; table 1 ). G-CSF remained significantly associated with diagnostic category $(\beta=-0.073 ; \mathrm{p}=0.008)$ following adjustment for age, sex, education and APOE status (table 2). To test for residual confounding by the APOE4 allele, an analysis was run after stratification of the sample on APOE4 status. Serum G-CSF was not significantly associated with disease status in either the APOE4-positive or APOE4-negative group. However, the $\mathrm{p}$ values were marginal (0.053 and 0.077 in APOE4-negative and APOE4-positive individuals, respectively), and the trends were consistent with those observed in the unstratified sample (data not presented).

Among AD participants only $(n=197)$, higher serum G-CSF levels were negatively associated with lower (worse) scores on the MMSE $(\beta=-0.178 ; \mathrm{p}=0.014$; table 3$)$ and posi- 
Table 7. Results for G-CSF from multivariate logistic regression analysis of G-CSF and MMSE scores among AD patients following stratification into tertiles on brain-derived neurotrophic factor (BDNF), C-reactive protein (CRP) and thrombopoietin

\begin{tabular}{|c|c|c|c|c|c|c|}
\hline \multirow[t]{2}{*}{ Protein } & \multirow[t]{2}{*}{ Tertile } & \multicolumn{2}{|c|}{$\begin{array}{l}\text { Unstandardized } \\
\text { coefficients }\end{array}$} & \multirow[t]{2}{*}{$\begin{array}{l}\text { Standardized } \\
\text { coefficient } \beta\end{array}$} & \multirow[t]{2}{*}{$\mathrm{t}$} & \multirow[t]{2}{*}{$\mathrm{p}$ value } \\
\hline & & B & Std error & & & \\
\hline \multirow[t]{3}{*}{ Thrombopoietin } & Low & 0.024 & 0.182 & 0.018 & 0.132 & 0.896 \\
\hline & Medium & -0.662 & 0.177 & -0.440 & -3.739 & $<0.001^{* *}$ \\
\hline & High & -0.252 & 0.207 & -0.159 & -1.218 & 0.228 \\
\hline \multirow[t]{3}{*}{ BDNF } & Low & -0.280 & 0.184 & -0.182 & -1.515 & 0.135 \\
\hline & Medium & -0.423 & 0.168 & -0.338 & -2.524 & $0.015^{*}$ \\
\hline & High & -0.132 & 0.186 & 0.086 & 0.712 & 0.479 \\
\hline \multirow[t]{3}{*}{ CRP } & Low & -0.121 & 0.168 & -0.093 & -0.720 & 0.475 \\
\hline & Medium & -0.069 & 0.174 & -0.051 & -0.399 & 0.692 \\
\hline & High & -0.722 & 0.195 & -0.450 & -3.699 & $<0.001^{* *}$ \\
\hline
\end{tabular}

Regression models included adjustment for age, gender, years of education and APOE4 status.

* Significant at $\mathrm{p}<0.05 ;{ }^{* *}$ significant at $\mathrm{p}<0.001$.

tively associated with higher (worse) scores on the CDR Global $(\beta=0.170 ; \mathrm{p}=0.018$; table 4$)$ and CDR Sum of Boxes ( $\beta=0.153 ; p=0.035$; table 5$)$.

In post-hoc analyses, serum G-CSF levels were tested for association with individual neuropsychiatric test score by multivariate logistic regression. Serum G-CSF concentration was significantly associated with only digit span among AD participants and delayed logical memory among controls (table 6). In an attempt to resolve the impact of a number of key processes that have been shown to be important to $\mathrm{AD}$ pathology, we performed a set of stratified analyses. First, we selected proteins that were representative of inflammation (Creactive protein; CRP), coagulation (thrombopoietin; THP) and neurotrophic factors (brain derived neurotrophic factor; BDNF). Next, we stratified the participants based upon tertiles for each of these proteins. Finally, we evaluated the association between G-CSF and diagnostic status (AD vs. NC) for participants within each group. Serum G-CSF levels were significantly associated with diagnostic status for participants in the mid-tertile for THP and BDNF. In contrast, G-CSF was associated with diagnostic status only for participants in the high-tertile for CRP (table 7).

\section{Discussion}

In addition to hematopoietic functions, G-CSF has a number of neuroprotective effects. With respect to $\mathrm{AD}, \mathrm{G}$-CSF increases the number of microglia, decreases $\beta$-amyloid deposition and reverses cognitive impairment in a mouse model $[15,16]$. In the present work, we sought to determine whether serum levels of G-CSF are associated with a diagnosis of AD or with disease severity among individuals with a diagnosis of probable AD.

In our primarily Caucasian cohort of individuals with a diagnosis of probable AD and NCs from Texas, we observed significantly lower serum levels of G-CSF protein among AD cases than controls. This observation is in agreement with others [17]. In follow-up analyses 
in the same cohort, we observed a significant positive association between serum G-CSF and disease severity, as measured by MMSE and CDR scores.

In agreement with the present study, Laske et al. [17] reported lower plasma G-CSF levels in early $\mathrm{AD}$ subjects relative to controls. Furthermore, these authors observed that, among AD patients, plasma G-CSF showed a significant inverse correlation with amyloid- $\beta$ (A $\beta 1-$ 42) levels in cerebrospinal fluid. Our results in a larger cohort confirm part of this prior work as we observed a significantly lower level of serum G-CSF among AD patients, compared to NCs. However, in contrast to Laske et al. [17], we found that increased serum G-CSF was significantly associated with greater disease severity. This difference between the present findings and those of Laske et al. [17] may be due to statistical power and sample size issues. While the previously published study analyzed samples from a total of 100 subjects (50 AD cases, $50 \mathrm{NCs}$ ), our results were based on 400 participants. Agreement in the direction of the association between G-CSF levels and increased disease severity among AD participants increases confidence in the results of the present study.

Other researchers, including ourselves, have observed an impact of APOE4 status on associations between various biomarkers and disease status [18]. However, in this instance, carriage of the APOE4 allele did not seem to influence the results. Although stratification of the sample negatively affected the tests by reducing the sample size and hence statistical power, all trends were in the same direction in both stratified and unstratified analyses.

\section{Conclusions}

In light of the neurotrophic and neuroprotective role of G-CSF, our results are consistent with the hypothesis that reduced G-CSF abundance contributes to AD pathology. Taken together, these observations raise the possibility that G-CSF is dysregulated early in the disease process and that the elevation in G-CSF observed in more advanced disease may represent a compensatory response. Future work by TARCC scientists will investigate this possibility through the analysis of longitudinal samples collected from the same participants over several years. These findings have implications for the design of clinical trials of G-CSF for the prevention or treatment of AD.

\section{Acknowledgements}

This study was made possible by the Texas Alzheimer's Research and Care Consortium (TARCC) funded by the state of Texas through the Texas Council on Alzheimer's Disease and Related Disorders. Investigators at the University of Texas Southwestern Medical Center at Dallas also acknowledge support from the UTSW Alzheimer's Disease Center (NIH, NIA grant P30AG12300).

\section{Disclosure Statement}

The authors have no actual or potential conflict of interest. 


\section{References}

1 Thomas J, Liu F, Link DC: Mechanisms of mobilization of hematopoietic progenitors with granulocyte colony-stimulating factor. Curr Opin Hematol 2002;9:183-189.

-2 Schneider A, Kuhn HG, Schäbitz WR: A role for G-CSF (granulocyte-colony stimulating factor) in the central nervous system. Cell Cycle 2005;4:1753-1757.

-3 Asano S: Human granulocyte colony-stimulating factor: its basic aspects and clinical applications. Am J Pediatr Hematol Oncol 1991;13:400-413.

-4 Schneider A, Krüger C, Steigleder T, et al: The hematopoietic factor G-CSF is a neuronal ligand that counteracts programmed cell death and drives neurogenesis. J Clin Invest 2005;115:2083-2098.

-5 Pitzer C, Krüger C, Plaas C, et al: Granulocyte-colony stimulating factor improves outcome in a mouse model of amyotrophic lateral sclerosis. Brain 2008;131:3335-3347.

-6 Li B, Gonzalez-Toledo ME, Piao CS, et al: Stem cell factor and granulocyte-colony stimulating factor reduce beta-amyloid deposits in the brains of APP/PS1 transgenic mice. Alzheimers Res Ther 2011; 3:8.

7 Sanchez-Ramos J, Song S, Sava V, et al: Granulocyte colony stimulating factor decreases brain amyloid burden and reverses cognitive impairment in Alzheimer's mice. Neuroscience 2009;163:55-72.

-8 Jiang H, Liu CX, Feng JB, et al: Granulocyte colony-stimulating factor attenuates chronic neuroinflammation in the brain of amyloid precursor protein transgenic mice: an Alzheimer's disease mouse model. J Int Med Res 2010;38:1305-1312.

-9 Bartolini A, Vigliani MC, Magrassi L, et al: G-CSF administration to adult mice stimulates the proliferation of microglia but does not modify the outcome of ischemic injury. Neurobiol Dis 2011;41: 640-649.

10 Folstein MF, Folstein SE, McHugh PR: 'Mini-mental state'. A practical method for grading the cognitive state of patients for the clinician. J Psychiatr Res 1975;12:189-198.

11 Morris JC: The Clinical Dementia Rating (CDR): current version and scoring rules. Neurology 1993; 43:2412-2414.

12 McKhann G, Drachman D, Folstein M, et al: Clinical diagnosis of Alzheimer's disease: report of the NINCDS-ADRDA Work Group under the auspices of Department of Health and Human Services Task Force on Alzheimer's Disease. Neurology 1984;34:939-944.

13 Simón-Sánchez J, Singleton A: Genome-wide association studies in neurological disorders. Lancet Neurol 2008;7:1067-1072.

14 O’Bryant SE, Xiao G, Barber R, et al: A serum protein-based algorithm for the detection of Alzheimer disease. Arch Neurol 2010;67:1077-1081.

-15 Kannengiesser K, Maaser C, Kucharzik T: Molecular pathogenesis of inflammatory bowel disease: relevance for novel therapies. Per Med 2008;5:609-626.

- 16 Borel C, Antonarakis SE: Functional genetic variation of human miRNAs and phenotypic consequences. Mamm Genome 2008;19:503-509.

-17 Laske C, Stellos K, Stransky E, et al: Decreased plasma levels of granulocyte-colony stimulating factor (G-CSF) in patients with early Alzheimer's disease. J Alzheimers Dis 2009;17:115-123.

18 Leoni V: The effect of apolipoprotein E (ApoE) genotype on biomarkers of amyloidogenesis, tau pathology and neurodegeneration in Alzheimer's disease. Clin Chem Lab Med 2011;49:375-383. 